\title{
PODER Y POLITTICA URBANA: UN BINOMIO INDISOLUBLE
}

M. ALEJANDRO SIFUENTES

Departamento de Metodologia y Tecnologia/UAA

Mario Bassols Ricárdez, Política urbana en Aguascalientes. Actores sociales y territorio (1968-1995), Instituto Cultural de Aguascalientes/Universidad Autónoma Metropolitana, Unidad Iztapalapa, México, 1997, 255 pp.

I

I/s curioso o inusual comenzar los comentarios a un libro como el que hoy me ocupa por su mensaje final. Es igualmente poco común encontrar en un texto, producto de una rigurosa investigación, voluntariosos llamados al rescate de "valores culturales, sociales y políticos", que en definitiva se ubican en una dimensión ajena al discurso académico, del que el libro en cuestión es pródigo a lo largo de sus páginas.

Pero esto que pudiera parecer extraño en otros investigadores, no lo es en el caso de Mario Bassols, quien es un enamo- rado del "talante" de los acaliteños y del paisaje urbano-arquitectónico de Aguascalientes. No en balde, apenas hay una oportunidad, Mario nos regala con su presencia en este rincón de la geografía mexicana para reafirmarse en los lazos afectivos que trascienden la mera curiosidad del científico social para elevarse en fidelidades apenas veladas: el abuelo de Mario, Don Narciso Bassols, contendió por la gubernatura de Aguascalientes en el año de 1919, iniciando así un affair con la ciudad que difícilmente nuestro autor ha podido negar.

Son esos afectos los que se respiran en las últimas páginas de su libro, y son tan pertinentes cuanto que invocan una dimensión frecuentemente olvidada por quienes nos dedicamos a estos menesteres: esa dimensión sobre la que Karel Kosik nos alerta en un ensayo publicado en Nexos: lo poético, y que a menudo encontramos 
en los "relatos de sabor antiguo" de los literatos aquicalidenses de épocas pretéritas.

"La ciudad y lo poético", el texto de Kosik, me sirve para adivinar en aquellos llamados voluntariosos de Mario esos afectos trastocados en pulsión por el rescate de la "arquitectónica" social para hacer frente a la bestia triumphans que, por mucho que el disidente checo del socialismo real no se quiera comprometer a nombrar, me atrevo a homologarla con el mercado endiosado, ese déspota que expulsa de la ciudad al poeta, para usar la misma metáfora de Kosik.

Pero no es mi intención colocar mi reseña en este divisadero. Por el contrario, si quisiera simplificar mi análisis del libro de Bassols en unos cuantos rubros, destacaría dos grandes aspectos: i) el modelo teórico; ii) los resultados de su aplicación concreta en una situación concreta. En ambos polos lanzaré algunos comentarios y observaciones, y consignaré algunas convergencias, divergencias, ausencias y presencias que la lectura de este texto sugiere.

II

Con todos los riesgos que implica la simplificación, necesaria bajos ciertas circunstancias, y a falta de una caracterización completa, me atrevo a aventurar que han existido cuando menos cuatro orien- taciones dominantes en la investigación urbana actual hecha en Aguascalientes por investigadores locales (exceptuando a los estudiosos del INEGI); las señalo sin orden alguno de importancia:

A) La propiamente historiográfica, es decir, aquélla soportada por autores como Jesús Gómez Serrano y Víctor González Esparza, cuyos objetos de estudio no necesariamente están relacionados con los procesos urbanos, dado que en sus trabajos la ciudad aparece como telón de fondo de procesos sociales bien delimitados y muy bien acotados, que tienen a la urbe como su espacio de acción, pero en los que no abunda el análisis urbanístico de variables clave.

B)La vertiente de los estudios del proceso de urbanización bajo las categorías demográficas y de desarrollo urbano regional, con una fuerte base estadística, entre cuyos autores destacan Alfredo Ortiz, Netzahualcóyotl López, Óscar Narváez, Graciela Castañeda y algún otro.

C)La línea de los trabajos tejidos alrededor del análisis del capital y del proceso de urbanización capitalista como determinado por factores tales como la renta del suelo urbano, el sector de promoción inmobiliaria o por categorías del análisis económico, entre cuyos exponentes cuento a Edith Jiménez, Arnoldo Romo y José Alfredo Santos, algunos trabajos de Ro- 
gelio Enríquez y otros del que esto escribe.

D)La vertiente quizá menos consolidada -pero no menos valiosa bajo ciertos aspectos- de estudios urbanísticos bajo diversos enfoques teórico-metodológicos de algunos investigadores del Centro de Ciencias del Diseño y de la Construcción de la Universidad Autónoma de Aguascalientes. Estudios todos a los que se viene a sumar ahora otro horizonte de análisis que explora la dimensión política, traducida a las políticas urbanas de los grupos hegemónicos en el poder, que en Fernando Salmerón y Mario Bassols, con este libro que reseñamos, tiene a dos puntales indiscutibles.

Desde luego, en esta ruda clasificación ni están todos los que son ni son todos los que están, pero al menos tiene la ventaja de destacar precisamente la emergencia de un nuevo tipo de estudios, como el abordado por Mario Bassols en este libro. Otros trabajos han abordado el tema desde perspectivas como la antropología urbana o la semiótica y la sociología de la cultura, sin que hasta el momento hayan tenido la continuidad deseada.

Política urbana en Aguascalientes. Actores sociales y territorio (1968-1995), es un libro con grandes aciertos cuya lectura, inevitablemente, remite a algunos trabajos sobre la "realidad urbana" del Aguas- calientes actual. Un elemental ejercicio de autocrítica puede comenzar a partir de los finos análisis sociológicos de Mario en torno a las políticas urbanas, ya que proporciona suficientes elementos para reconocer las limitaciones de los estudios previos en el terreno de lo político y en esa medida ponderar la riqueza de los argumentos y tesis centrales del libro de marras. A pesar de todo, encuentro que los análisis de la ciudad de Aguascalientes, desde la perspectiva "economicista", no desentonan con algunos de los argumentos esenciales de Bassols.

Página tras página, el texto de Bassols logra interesar al lector con notables análisis in crescendo, conforme el autor se va acercando a su objeto. Creo que el discurso científico no está reñido con un lenguaje aseado y una buena escritura; y tampoco con la escritura que teje la exposición de un modo que apasiona al lector y que lo deja esperando con ansia la lectura del siguiente capítulo. La pasión que provoca la lectura es, pues, uno de los primeros aciertos de esta publicación.

\section{III}

Después del descrédito forzado e ideologizado que el socialismo real alentó en el ámbito académico, los paradigmas de la investigación social han pasado de la explicación de las macroestructuras a la de fe- 
nómenos particulares. Por ello es de notar el intento de Bassols por construir un modelo teórico que a la vez que dé cuenta de una situación particular, apunte a explicar tendencias registradas a nivel global en las ciudades medias mexicanas. Ello nos remite, indefectiblemente, a su modelo teórico y a sus posibilidades de aplicación.

A fin de generar su propia propuesta, Bassols se ve precisado a revisar dos de las contribuciones teóricas que más calaron en el campo de la investigación urbana desde los años setenta: la de Manuel Castells y la de Jean Lojkine.

Pareciera natural comenzar el análisis sociológico de las políticas urbanas por el examen de los conceptos que sobre el particular redefinió el sociólogo español Manuel Castells. Y lo digo así por el papel fundamental que su libro La cuestión urbana representó para la investigación urbana de corte marxista (estructuralista, en este caso) en Europa y Latinoamérica, cuyas proposiciones han sido reconsideradas por el mismo autor en sus últimos trabajos.

Pareciera natural también seguir el recorrido de la investigación materialista por los senderos de la crítica que sobre las nociones de los medios de consumo colectivos y la reproducción de la fuerza de trabajo, Lojkine hiciera a Castells.
Lo que no parece consecuente, cuanto y más tratándose de un autor mexicano, es que el "ajuste de cuentas" que Bassols hace con esta tradición de investigación deje de lado la contrarréplica que Emilio Pradilla hace a la "réplica" que Lojkine dirigió a Castells. Desconozco las razones, pero no es improbable cierto estructuralismo que parece deslizarse bajo la propia propuesta de Pradilla y tal vez hasta un cierto dejo ideológico inaceptable para Mario. En suma, Bassols nos propone, metodológicamente, "salir para entrar"; se colije que de ese marxismo estuctural-funcionalista castellsiano y de la sobrevaloración del papel del Estado en la urbanización capitalista (que en la fase histórica que le tocó analizar a Lojkine parecía comprensible, pero que hoy se desmorona ante el capitalismo "global"), aunque da la impresión de que con una discusión todavía insuficiente de otras aportaciones teóricas, aún dentro del marxismo y por supuesto fuera de él.

A pesar de todo, la propuesta de Bassols de estudiar al Estado a través de las políticas urbanas en un contexto histórico específico, "no como un agente separado de las relaciones sociales e intereses de la clase en pugna, sino en estrecha relación con el sistema político que rige a la sociedad", se antoja refrescante en el ámbito local, sobre todo por el análisis de 
otros actores sociales además del aparato burocrático y de ejercicio del poder estatal, tales como organizaciones corporativas, partidistas y de colonos, aunque quizá, en este sentido, se extraña un poco en el texto a los terratenientes urbanos, a los promotores inmobiliarios y agentes que aseguran el cambio de uso de suelo en los procesos de urbanización capitalista.

No pueden eludirse aquí dos puntos polémicos: por un lado, la consideración del Estado como agente que "se separa del conjunto para representar a las otras fracciones a través de su carácter estatal" y, por otro, a la consideración del Estado no sólo como "garante" sino como productor de las condiciones generales de la producción.

En el primer caso, siguiendo a Bruno Thèret, no es que el Estado esté separado en el sentido literal, como entidad autónoma del capital, sino tan sólo que es expresión de una fracción hegemónica de la burguesía que asume un carácter estatal para controlar y dirigir el proceso de reproducción de la dominación políticoideológica más adecuada al capital, como afirma Pradilla, pero también (y aquí lo ligo con el segundo punto) para producir las condiciones generales de la producción, ya que muchos de los sistemas infraestructurales (energía, transporte de mercancías, comunicaciones) aparecen efectivamente como colectivos, pero no dejan de ser consumidos productivamente por el capital, entrando por ello en el proceso inmediato de producción como prolongación de la producción, transfiriendo por tanto valor a los valores de uso producidos. El análisis del gasto público y de las inversiones en infraestructura que los gobiernos de Landeros y Barberena llevaron a cabo en sus sexenios, sin que costara un centavo a las compañías transnacionales, permite concluir que el Estado, y su fracción hegemónica en el poder en esos años, no sólo produjo las condiciones de reproducción de la fuerza de trabajo (el amplio programa de vivienda popular) y de la dominación jurídico-política-ideológica (uno de cuyos puntales fue la ideología urbanística, consolidada por Oscar López Velarde y sus instrumentos legales), sino que también produjo las condiciones generales de la producción que llevaron a la transformación de la ciudad "en aras del proyecto económico del grupo en el poder", con un conjunto de políticas territoriales fragmentadas que, "articuladas al nuevo proyecto de desarrollo industrial, fomentaron la centralización del poder político y económico en la ciudad capital del estado", como afirma Bassols; es decir, en otras palabras, que el uso capitalista que se ha hecho de la ciudad de Aguascalientes en los últimos años coman- 
da la reproducción ampliada del sistema urbano y regional; esto es, la concentración económico-espacial y la subordinación del resto del territorio a la ciudad. Aunque desde luego concedo con el autor que la problemática del poder político, tal como él lo plantea, está ausente en los análisis de tipo "economicista".

Como esquema experimental, es evidente que el modelo teórico propuesto por Bassols está en construcción y que presenta aspectos que desde luego no aparecen en el texto. Encuentro que algunos de sus elementos tan sólo están enunciados pero no han sido desarrollados teóricamente, y mucho menos históricamente. Pienso por ejemplo en la dimensión cultural. También es de notarse la ausencia de una explicitación de la "teoría de los determinantes negativos comunes" y su rol en el curso del plan de investigación, que no queda suficientemente claro en la exposición.

Ligado con lo anterior, hay un punto más respecto al modelo teórico que vale la pena comentar. Creo que hubiera sido deseable una nota o apartado metodológico en donde el autor discutiera más acuciosamente el esquema sobre el estudio de las políticas urbanas que se presenta en la página 49 , sobre todo para aclarar la manera cómo los niveles y dimensiones de la política urbana se entreveran con las políticas mismas y con la estructura y el ejercicio del poder. En suma, más que conocer el "cómo se le va a entrar", interesaría el "cómo se le entró" efectivamente al problema y qué tanta correspondencia hubo entre el análisis real y los presupuestos teórico-metodológicos. Menciono esto por la necesidad de discutir el modelo mismo en su armazón, y determinar su grado de efectividad en su aplicación concreta. Al no existir ese apartado, el autor nos ha privado de la oportunidad de discutir la bondad del modelo mismo y por tanto de determinar su grado de cientificidad.

IV

Al margen de lo anterior, donde se revela el gran oficio de sociólogo urbano de Mario Bassols, perfectamente adecuado a su objeto de estudio, es en el apartado 2.3 y en los capítulos 3,4 y 5 . Ahí no sólo se observan cualidades analíticas notables y perspicaces acotaciones al sistema político aquicalidense, sino que además la lectura es francamente apasionante, alcanzando a mi juicio niveles de brillantez expositiva y a la vez de gran profundidad explicativa, particularmente en los apartados de vivienda y política urbana, inquilinos y colonos. Me detendré un poco en cada uno de estos capítulos para hacer una síntesis de los argumentos que me han parecido más relevantes, y proponer algunas aco- 
taciones casi marginales, pero a mi juicio pertinentes.

Sobre la base de la tesis, por lo demás ampliamente demostrada en el curso de la exposición, de que la estructura de poder subyace a todo estudio sobre políticas urbanas del Estado, y las consideraciones del papel señero de la variable del sistema político, y las peculiaridades de éste según su nivel local o nacional, Bassols nos introduce en el estudio de las relaciones específicas existentes entre el desarrollo de las políticas urbanas y la conformación de la sociedad local, lo que lo lleva a analizar los diferentes períodos gubernamentales y sus equipos políticos dirigentes, con sus actores principales, sin dejar de incorporar en su examen otros agentes del sistema político.

Los ejercicios de planeación urbana, con alguna pretensión integral, efectivamente parten, como afirma Mario, en 1948 con el Plano Regulador de Carlos Contreras. Sin embargo, no pueden ser pasados por alto dos antecedentes fundamentales: las Ordenanzas de Población de Felipe II, de cuya aplicación en la villa de Aguascalientes existen evidencias, y el famoso Plano de las Colonias, que a pesar de su declarado (¿descarado?) objeto mercantil, intentó regular (si bien a posteriori) el desarrollo urbanístico de toda la zona oriente, aledaña a los Talleres Generales de Repara- ción del Ferrocarril Central, bajo un plan urbanístico inspirado en el Plan del Prefecto de París, el barón de Haussman, cincuenta años antes. Demuestra lo anterior el hecho de que el modelo más inmediato, cuyo referente también fue el plan parisino, fue la experiencia urbanística de la Colonia Juárez en la ciudad de México, en la que participó precisamente Samuel Chávez, el autor del Plano de las Colonias.

Poco a poco, Bassols nos va llevando por los inicios de la constitución, auge y decadencia de las políticas urbanas del Aguascalientes moderno, analizando el viraje del sistema de alianzas entre los grupos políticos locales a partir del sexenio 1962-1968, en donde surge un nuevo grupo con evidentes vínculos con el poder central (léase federación), y que poco a poco preparó las condiciones para la entrada a una nueva fase de expansión económica y urbana. Así, en ese sexenio, el gobierno de Enrique Olivares Santana destinó el $70 \%$ del gasto ejercido a la infraestructura, primordialmente de la capital, lo que constituye un dato revelador.

Desde entonces comienzan los intentos por regular la venta de terrenos (llevada a cabo por fraccionadores clandestinos) a través de las instancias de gobierno; sin embargo, aún no estaba desarrollado el marco jurídico de la planeación urbana, que, al menos en (cándida) teoría, garan- 
tizaría el fin de la especulación indiscriminada.

El sexenio del Dr. Guel Jiménez significó el surgimiento de los primeros equipos de planeación con una visión evidentemente técnica-profesional, aunque de escasa incidencia política. Por ello, como acertadamente dice Bassols, la planeación y la política urbana, al dejar intactos los mecanismos de especulación y renta del suelo, difícilmente lograron la regulación esperada. Si lo jurídico se erigía como un obstáculo, los siguientes sexenios (Esparza Reyes, Landeros Gallegos y Barberena Vega) terminaron por adecuar lo jurídico a las políticas respondiendo no a los intereses mayoritarios de la población, sino a los intereses de grupos en el poder con ligas centrales. Cabe aquí una consideración que puede ser útil. En el perspicaz análisis que hace Mario de los equipos de planeación quizá faltó considerar el hecho de que el gobierno de Esparza Reyes contara, por primera vez, con un equipo de planeación formado bajo los principios urbanísticos de la ciudad moderna, esto es, el urbanismo funcionalista, una de cuyas características era la visión aséptica y neutral de las relaciones sociales en el territorio. Debe tenerse en cuenta además que la fundación del Colegio de Arquitectos data de 19671968 y que sus cinco miembros fundado- res fueron formados en esta tendencia, la de la arquitectura y el urbanismo del Movimiento Moderno. No es de extrañar, pues, que comenzaran a presionar por tener cierta injerencia en la planeación urbana, logrando incrustarse en el gobierno de Esparza Reyes. Fue precisamente su Director de Planeación y Construcciones, el Arq. Mario García Navarro, quien junto con casi los mismos miembros de su equipo fundó la carrera de Arquitectura de la UAA en 1974. A pesar de todo, como bloque no eran expresión de los principales grupos constructores o especuladores urbanos. Como sugiere muy acertadamente Mario Bassols, esta visión técnica podría explicar las demandas de regulación de la especulación.

Cuando nuestro autor aborda el asunto de las políticas de vivienda nos regala, a mi juicio, su más brillante análisis. Desde tiempo atrás la política de vivienda y los programas habitacionales populares quedaron definidos en función de las relaciones entre la burocracia sindical y los industriales de la construcción, lo que significa, ni más ni menos, que prevalecían mecanismos de clientelismo electoral alrededor de reivindicaciones sociales básicas, tales como la vivienda. Durante mucho tiempo el corporativismo campeó como uno de los mecanismos de sujeción y control político de las demandas de la población: el 
propio sistema de alianzas y el carácter mismo del poder casi total de los gobernadores en turno lo permitió. Así, la CNOP primero, a través del Instituto Nacional de la Vivienda, y la CTM-FTA, a través del INFONAVIT y el INDECO, constituyeron las estructuras de mediatización política de las demandas populares.

Brillante también es el apartado de las organizaciones de vecinos y colonos, que al ser cooptadas por los mecanismos corporativistas no dejaron de ceñirse a lo que el autor llama una "ideología viviendista": eran tiempos en que los organismos de vivienda aún podían financiar las unidades de habitación en su modalidad de "vivienda terminada"; la institucionalización de los procesos de autoexplotación de la fuerza de trabajo en la producción de la propia morada vendría después con la modalidad de la "vivienda comenzada" (lotes con servicios y pies de casa).

Notable es también el análisis de la entrada en crisis del modelo urbano caciquil de gestión de la vivienda, consignando el autor una primera fase de debilitamiento que permitió la emergencia del Frente Estatal de Acción Popular y que activó los procesos de poblamiento popular insurgente fuera de los marcos establecidos por los mecanismos corporativos del Estado. A estas alturas, según los personeros de la política local, era ya irrevo- cable la consigna de reorientar la acumulación por la vía de la modernización capitalista de Aguascalientes, aunque Bassols introduce una consideración que a mi juicio admite un matiz. Afirma que dicha modernización fue el producto no tanto de las tendencias de desarrollo de la economía cuanto reflejo de una lucha por el poder hegemónico del aparato estatal. Bien vistas las cosas, tanto dichas tendencias como aquella sorda lucha son elementos que pueden explicar integralmente el fenómeno: una no se opone a la otra, son complementarias; lo que el autor ha hecho es poner de relieve, correctamente, algo que se había perdido de vista: la indisoluble relación entre lo político y lo urbano.

En esta coyuntura apareció el Plan Director Urbano de la Ciudad de Aguascalientes (1980), nuevo "elemento de poder" y "carta de negociación política" respecto a los futuros asentamientos. De hecho, el Plan se había formulado desde el sexenio de Esparza Reyes; sin embargo, la primera invasión a Las Huertas significó un serio revés a los intentos reguladores del crecimiento. Landeros Gallegos abrió pues con el Plan Director. Su operación requería una reestructuración del aparato planificador y de gestión de la política industrial, por lo que la Dirección de Planeación y Construcciones se transformó en Secreta- 
ría de Planeación y Desarrollo Estatal, con Oscar López Velarde a la cabeza. Mientras tanto, Carlos Lozano de la Torre se hizo cargo de la Dirección de Fomento Industrial, dependencia que tuvo un papel fundamental en la gestión de la modernización capitalista y la orientación de las inversiones hacia suelo hidrocálido. En la SEPLADE el equipo técnico planificador desapareció, abriendo el campo a arquitectos improvisados. En cambio, se fortaleció un organismo igualmente toral: la Junta General de Planeación y Urbanización del Estado, la que en suma tendría la función de actuar como agente intermediador entre las políticas de suelo urbano y la lógica comercial del mercado inmobiliario privado. La Junta fue asimismo un puntal en la promoción de la ideología urbanística, base del discurso planificatorio gubernamental, que tuvo en López Velarde su principal ideólogo.

La estrategia del Plan Director de inducir el crecimiento hacia los lomeríos del oriente, si bien desde un punto de vista estrictamente urbanístico fue adecuada e históricamente eficaz, significó, como lo establece muy acertadamente Mario Bassols, la reorientación del proceso de urbanización hacia zonas de mayor control político del poblamiento (y por ende del uso del suelo y la lógica especulativa). No bien pasaron tres años, una nueva conflagración (el "primer gran cisma de la nueva política urbana") hizo temblar el esquema planificatorio: la segunda invasión a Las Huertas, ante el vacío de control político dejado por la crisis del sistema caciquil urbano, coyuntura aprovechada por el PST para encabezar la insurgencia urbana y alimentar sus propios mecanismos clientelares. A raíz de lo anterior, y a efectos de mantener el control político del poblamiento, la inducción del crecimiento hacia la zona de ejidos implicó en los hechos el freno a la urbanización periférica incontrolada (caso Las Huertas) para adecuarla a los esquemas de planeación (caso Ojocaliente). Como bien lo menciona Bassols, aquí terminó por consolidarse la contradicción entre la regularización de los procesos de ocupación/ transformación del suelo y la política agraria que a principios de su administración había guiado los afanes del gobernador Esparza Reyes. Cabría preguntarse si esta situación no apuntaría a tendencias más generales que desembocarían en la ofensiva contra el artículo 27 constitucional.

Landeros comprendió bien la coyuntura: para evitar nuevos brotes de tensión social, confeccionó un gran programa de vivienda popular, que de hecho desde 1975 se había prefigurado, al reconocerse oficialmente por primera vez el problema habitacional. En el análisis del Programa 
de Vivienda, Bassols ofrece importantes datos que sugieren pistas para la investigación.

No puedo dejar de mencionar mi desacuerdo con el autor cuando señala la "ausencia de un manifiesto proceso de metropolización". Entiendo que deben pesar mucho en su percepción las proporciones magalopolitanas de la ciudad de México y sus tendencias de voracidad territorial, pero hasta con los mismos indicadores utilizados por investigadores nacionales como Boris Graizbord ha quedado plenamente establecida la tendencia metropolizadora de la capital estatal. Así, la conurbación con Jesús María es una realidad y no, como dice Bassols, algo que está dando los "primeros signos" de su existencia. Con la creación del corredor industrial norte-sur, con su "estructura típicamente especulativa", se implantaron las bases de la tendencia de suburbanización periférica metropolitana y se consolidó el peso abrumador de la capital sobre el resto del territorio, localidades y centros urbanos de menor rango, lo que abona la hipótesis de la metropolización, que el mismo Bassols termina por validar al constatar la ausencia de un auténtico sistema de ciudades.

Nuestro acucioso investigador termina estableciendo un período de estabilidad política que significó el recambio en el patrón de acumulación, aunque apunta que las relaciones de poder entre la burocracia y los empresarios no sufrieron ninguna alteración. También afirma que si durante 1980-1995 se observa una unidimensionalidad política en la gestión pública del poblamiento, del último año en adelante se asiste a proyectos alternativos de ocupación del espacio que frenaron el liderazgo gestor prísta en las colonias populares, sobre todo a partir de la colosal fractura de la hegemonía tricolor en el Congreso, la capital y algunos de los ayuntamientos del estado.

Entre los problemas que la gran expansión territorial ha provocado en los habitantes hay uno que no ha sido ponderado por Bassols. Al lado del el gran problema del agua, el agrietamiento y la fractura del subsuelo, como todos sabemos, han tenido funestas consecuencias sobre las viviendas de diversos sectores sociales. Aquí surge un nuevo reto para la investigación en la línea trazada por el autor, pero referente a las políticas de vivienda ante la contingencia de fenómenos naturales (aunque inducidos por la sociedad) y las posibles formas de organización vecinal de la sociedad civil frente al inmovilismo del aparato de planificación y frente a las nuevas formas -fraudulentas algunas- de la promoción inmobiliaria capitalista y de la mercantilización de la 
vivienda. Otro asunto más para el que el modelo de Bassols se presta es el análisis de la planeación urbana y las relaciones de poder bajo el proceso de concesión de las estaciones de servicio (léase gasolineras). Debido a su contemporaneidad, esos problemas podrían estimular nuevos proyectos de investigación. En este sentido, el. libro de Bassols ofrece una guía metodológica que no puede echarse en saco roto.

\section{V}

En conclusión, diría que el libro de Bassols es excelente en cuanto a la profundidad del análisis y el examen de la realidad local. Sin embargo, lo siento un tanto balbuceante en el modelo teórico, aunque no puede perderse de vista que es un armazón en construcción, y que por eso mismo cae en el terreno de lo discutible. No en el sentido descalificador del término, sino en la medida en la que el debate lo seguirá enriqueciendo. Por lo demás, el texto está pletórico de sugerentes pistas de investigación y tiene una cualidad hasta cierto punto rara en el medio académico, pues su lectura resulta fácil y hasta placentera. 